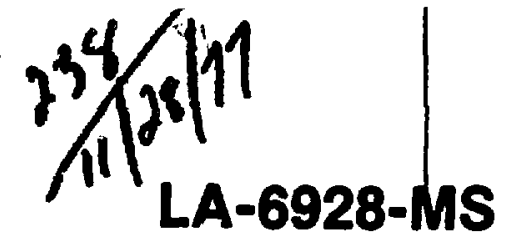

Informal Report

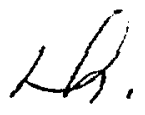

1613

UC-25

Issued: November 1977

\title{
Graphite-to-Metal Bonding Techniques
}

Lloyd O. Lindquist

Richard Mah

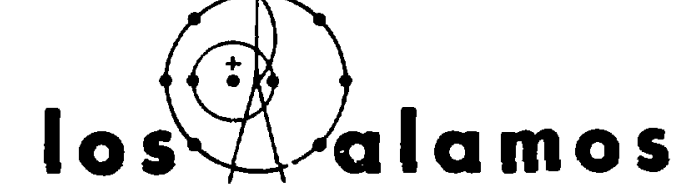

scientific laboratory of the University of California LOS ALAMOS. NEW MEXICO 87545

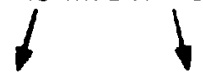

An Alfirmative Action / Equal Opporlunity Employer 


\title{
GRAPHITE-TO-METAL BONDING TECHNIQUES
}

by

Liloyd O. Lindquist and Richard Mah

\begin{abstract}
ABS'TRACT
We report the results of various bonding methods to join graphite to different metals. Craphite/metal bonds were tested for thermal flux limits and thermal flux cycling lifetimes. The most successful bond transferred a heat flux of $6.50 \mathrm{MW} / \mathrm{m}^{2}$ in more than 500 thermal cycles. This bond was between pyrolytic graphite and copper with Ti-Cu-Sil as the bonding agent.
\end{abstract}

\section{SUMMARY}

Physical and thermal bonding techriques to mate pyrolytic graphite to copper were tested for suitability in extracting high heat flux loads through the bonds. The most successful bonds were titanium-copper-silver and titanium-copper-nickel braze alloys. Their heat flux capabilities were $\sim 6 \mathrm{MW} / \mathrm{m}^{2}$, and they appeared to withstand indefinite heat cycling at maximum heat flux.

\section{INTRODUCTION}

At the Clinton P. Anderson Meson Physics Facility (LAMPF) at the present time, all Line A pion production targets are radiatively cooled. As beam currents rise from present levels $(\sim 300 \mu \mathrm{A})$ in Line $\mathrm{A}$, the surface temperature levels of the graphite targets will exceed $2300 \mathrm{~K}$. At temperatures above $2300 \mathrm{~K}$, graphite begins to evaporate at unacceptable rates (shown in Fig. 1). The A-5 bar proton target in its present configuration will approach this temperature at $300 \mu \mathrm{A}$, with an $800-\mathrm{MeV}$ proton beam. Rotating target wheels of the present design installed at A-1 and A-2 will rot exceed $1500 \mathrm{~K}$ for $800-\mathrm{MeV}$ proton currents of $1 \mathrm{~mA}$. If the target wheels are not spinning, then they too will experience higher temperatures, $>2300 \mathrm{~K}$ (see Fig. 2 ).

The thrust of this investigation has been to develop a metal-graphite interface to transfer heat from the graphite to a coulant, pumped adjacent to the metal. We are initially working with pyrographite, since the maximum pion production per centimeter of material minimizes the dose time for experiments. Pyrographite is the most dense form of graphite, and therefore has maximum pion production per centimeter of material. Some compeiling reasons for selecting this material are the low- $Z$, the high thermal conductivity, the high strength at elevated temperatures, and the ligh melting point $\left(3500^{\circ} \mathrm{C}\right)$. 


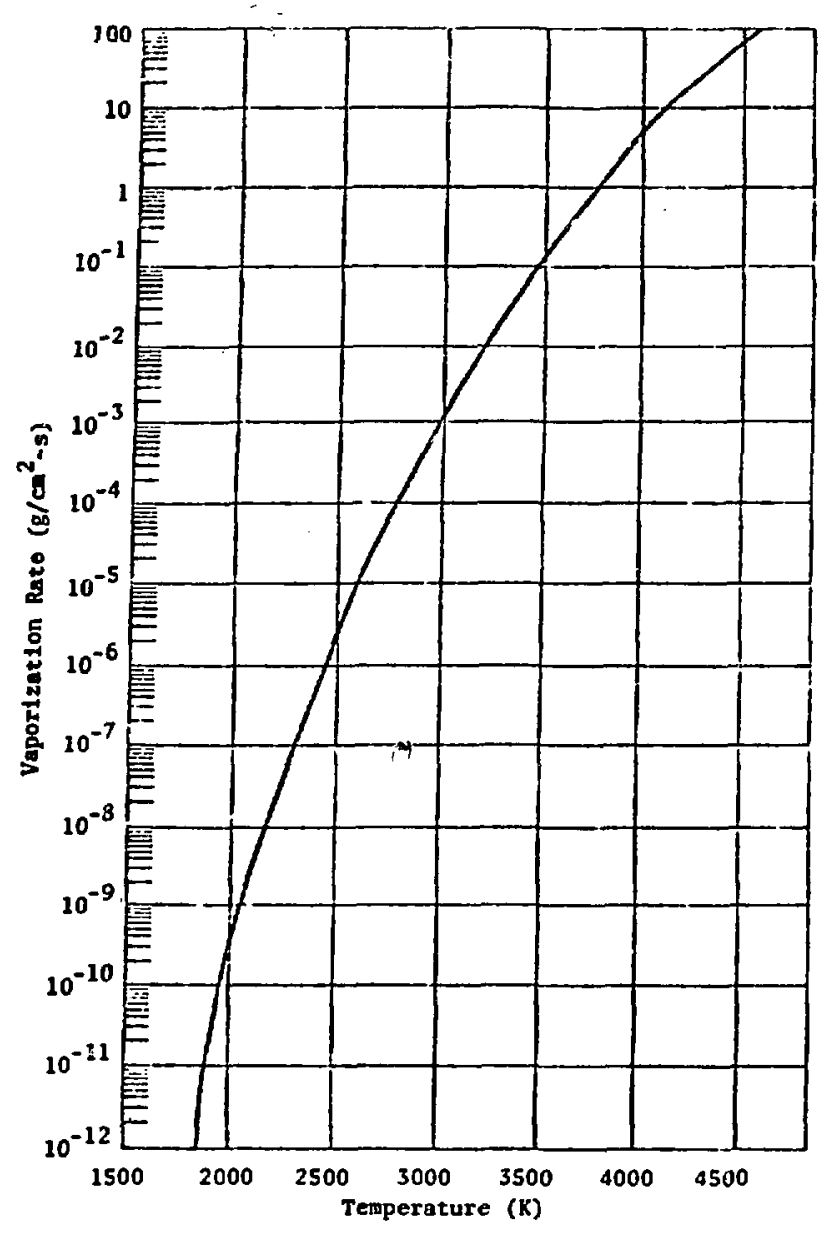

Fig. 1.

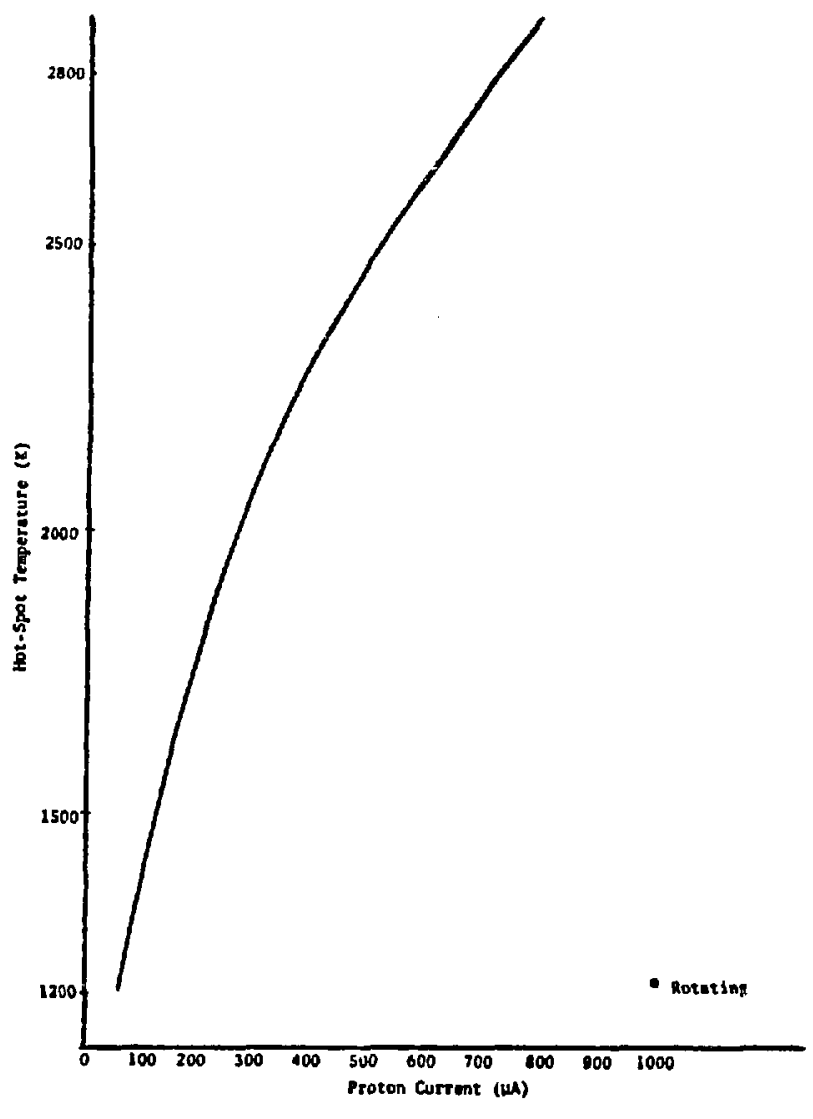

Fig. 2.

A.2 stationary target (ATJ graphite), temperature us proton current $\left(\rho=1.7 \mathrm{~g} / \mathrm{cm}^{3}\right)$.

Grophite evaporation rate us temperature of graphite surface.

\section{A. Bonding Techniques}

We have investigated in parallel several types of thermal bonding approaches. To date, we have made bonds between a metal $6.35-\mathrm{mm}$-diam (nominal) tube and a graphite cylinder with a hole drilled for the tube (shown in Fig. 3).

The first type of bond tested was polyfurfuryl alcohol (Varcum) graphitized in the space between a copper tube and pyrographite cylinder. The graphitization process bonds the pyrographite to the Varcum. The bonding of the Varcum to the pyrographite occurs while the assembly is held at $200^{\circ} \mathrm{C}$ for $60 \mathrm{~h}$ to achieve graphitization. The copper tube does not react chemically with the Varcum. Varcum merely fills the voids between the pyrographite and the copper tube, and may even mechanically prestress the copper tube during graphitization. This could explain the thermal flux capability of the bond (described later in this report). Two hybrid Varcum compounds were prepared in an attempt to improve on the thermal conductivity of an ordinary Varcum bond. One compound was composed of a heterogeneous mixture of fine aluminum chips and graphitized polyfurfuryl elcohol (Varcum) in the iabricated form. The assemblies that were fabricated using the hybrid compounds are described in Fig. 3. 


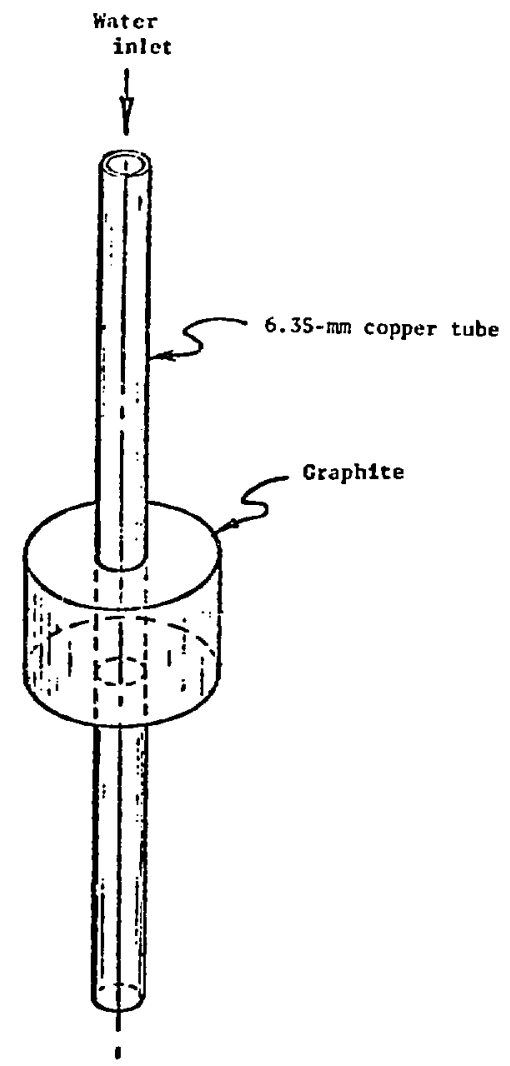

Fig. 3

Sample for testing graphite-to-copper bonding techniques in an induction heating assembly.

The second hybrid compound used fine copper chips instead of the aluminum chips, in order to improve the thermal conductivity of the heterogeneous mixture as well as to increase the maximum operating temperature of the bond. Copper melts at $1083^{\circ} \mathrm{C}$; aluminum melts at $660^{\circ} \mathrm{C}$. If the bond exceeds the melting point temperature of the aluminum, it will melt out of the graphitic matrix.

The Varcum preparation technique, compositions, and fabrication procedures are described in Appendix A.

A second method of bonding graphite to metal was electroplating copper to the interior of the graphite hole, then brazing the tube to the copper-plated graphite in a conventional vacuumbrazing furnace with $\mathrm{B}^{\prime} \mathrm{T}$ (copper-silver) brazing alloy. The electroplating operation was performed with standard copper solutions at normal plating rates for metals, to a thickness of $127 \mu \mathrm{m}$. No special techniques were used in the brazing operation. The braze occurred between the plated copper present on the graphite and the copper tube. This technique was atternpted since the mechanical roughness of the graphite surface contributes to a mechanical bond; also, the van der Waals forces (between the plated copper atoms and the carbon atoms) added to the strength of the bond as well as to the thermal conductivity. The brazing history is outlined in Appendix $B$. 
The third approach to bonding graphite to metal was to purchase* and test commercial bonding compounds. These carbon-based, thermally conductive compounds were tested and fabrication proceeded according to manufacturers' directions (see Fig. 3). One compound was Grade GC Graphite Cement and the other was a thermal putty compound. The preparation history is found in Appendix B.

A fourth bonding technique attempted to braze the graphite and metal tube directly together (Fig. 3). Two braze alloys, Ti-Cu-Ni and Ti-Cu-Sil, ${ }^{* *}$ that have successfully bonded copper and pyrolytic graphite (in the configuration shown in Fig. 3) were used; chemical compositions are shown iil Table I. Although these braze materials are referred to as alloys, they are not solid solutions. They are actually sandwiches of three different metal foils rolled together to form what we have called braze alloys. The hrazes were made in a conventional vacuum braze furnace, and studies were made to determine the optimal time-at-temperature braze. These studies showed that a temperature of $900^{\circ} \mathrm{C}$ for 5 min produced the best bond when brazing copper to pyrolytic graphite with Ti-Cu-Sil. When using the Ti-Cu-Ni braze, a temperature of $980^{\circ} \mathrm{C}$ for 2 min produced the best bond. Bond evaluations were made by macroscopically examining a longitudinal section of the brazed part for braze alloy flow and integrity. Subsequent work using the same variables with the same braze alloys showed that copper could be brazed successfully to ATJ graphite.

In the braze alloy, the titanium reacts with some of the graphite and forms an interface (TiC). The remainder of the braze alloy forms a solid solution with the TiC and the copper tube. Since titanium is a reactive metal, the same property that makes the braze alloys outstanding makes them difficult to work with. If the braze alloys - especially $\mathrm{Ti}-\mathrm{Cu}-\mathrm{Ni}$ - were allowed to react with the copper tube for too long a time, the titanium would produce holes or thinned sections in the wall of the copper tube. Nevertheless, a strong mechanical and thermal bond can be produced if carefully controlled.

Efforts are under way to braze various elemental and alloy tubes to graphite with the same braze alloys (Ti-Cu-Sil and $\mathrm{Ti}-\mathrm{Cu}-\mathrm{Ni}$ ). This will widen the selection of materials that can be bonded to both ATJ and pyrolytic graphite. Other elements and alloys will further widen the selection of heat transfer fluids and, therefore, applications. Studies are being made to determine the optimal time-at-temperature conditions for this furnace with tantalum, stainless steel, and molybdenum. Copper and ATJ graphite have also been successfully brazed with $\mathrm{Ti}-\mathrm{Cu}-\mathrm{Ni}$ and Ti-Cu-Sil. The general brazing temperature has been $900^{\circ} \mathrm{C}$, with typical vacuum braze times from 1-10 min (see Appendix B for details).

"Dyion Industries, Inc., Cleveland, OH 44162.

* Purchased from Western Gold \& Platinum Company, Belmont, CA 94002

TABLE I

CHEMICAL COMPOSITION OF BRAZE ALLOYS

\section{Ti-Cu-Sil Ti-Cu-Ni}

Titanium

Copper

Silver

Nickel
4.5

26.7

68.8
70.0

15.0

-...

15.0 


\section{B. Photographic Examination of Bond}

Figures 4 and 5 are photomicrographs of pyrolytic graphite brazed to copper with $\mathrm{Ti}-\mathrm{Cu}-\mathrm{Ni}$. The magnifications are $100 \mathrm{X}$ and $250 \mathrm{X}$, respectively. The lightest section in each photograph is the copper tube; the light gray is the braze zone; and the dark gray is the pyrolytic graphite. There was no evidence of the bond breaking or being discontinuous. Figure 6 shows a broken portion in the brazed joint; the fracture is located in the pyrolytic graphite region. This clearly indicates that the braze joint is stronger than either mating material (copper and pyrolytic graphite). These photographs were taken after the braze joint hal experienced more than 200 heat cycles of $6.50 \mathrm{MW} / \mathrm{m}^{2}$ heat flux. Clearly, this bond has promise for further development and application.

\section{Heat Transfer Testing Techniques}

The initial heat deposition method selected was high-frequency induction heating of graphite specimens bonded to various metal tubes (see Fig. 3). The heights of the graphite cylinders varied from 12.7 to $76.2 \mathrm{~mm}$. The outside diameters of the graphite cylinder and the tube were 22.2 and $6.35 \mathrm{~mm}$, respectively.

The specimens were placed in the induction heating apparatus (see Fig. 3). The volume inside the quartz tube was evacuated to pressures of $1 \times 10^{-6}$ to $5 \times 10^{-4} \mathrm{~mm}$ of mercury.

Water flowed through the tube at rates from 1.9-11.36 l/min; inlet and outlet water temperatures of this system were measured to $\pm 1 / 8 \mathrm{~K}$.

The total amount of power deposited in the graphite sample is the sum of the power deposited in the water [volume/minute $\times$ density $\times$ heat capacity $\times(T$ outlet $-T$ inlet)] plus the power dissipated radiatively through the vacuum to the surroundings [power $=$ emissivity $\times \sigma \times$ area $\left.X\left(T_{\text {surface }}-T_{\text {aurroundings }}^{4}\right)\right]$, where $\sigma=$ Stephan-Boltzmann constant. There is no opportunity for heat to transfer from the graphite to the surroundings in any other way in our experiment. Heating power to the graphite was controlled by adjusting the amount of power available to the radio frequency oscillator power circuit.

Power transmitted to the graphite load was measured by monitoring the water flow rate through the tube, the $\Delta \mathrm{T}=$ ( $\mathrm{T}$ inlet $-\mathrm{T}$ outlet $)$, and the surface temperature of the graphite (measured by an optical pyrometer for temperatures $>700^{\circ} \mathrm{C}$ ).

\section{Results of Heat Transfer Studies}

Each bonding method was tested to determine maximum heat flux capability through the bond. The results are shown in Table $I$.

\section{ACKNOWLEDGMENTS}

We wish to express our appreciation to the following Los Alamos Scientific Laboratnry people for their technical expertise in these tests: Donald E. Hull, high-frequency induction heating; Jimes R. Bradberry, metallography; John Russell, vacuum furnace brazing; and Donald $\mathbf{H}$. Schell, Varcum bonding techniques. 


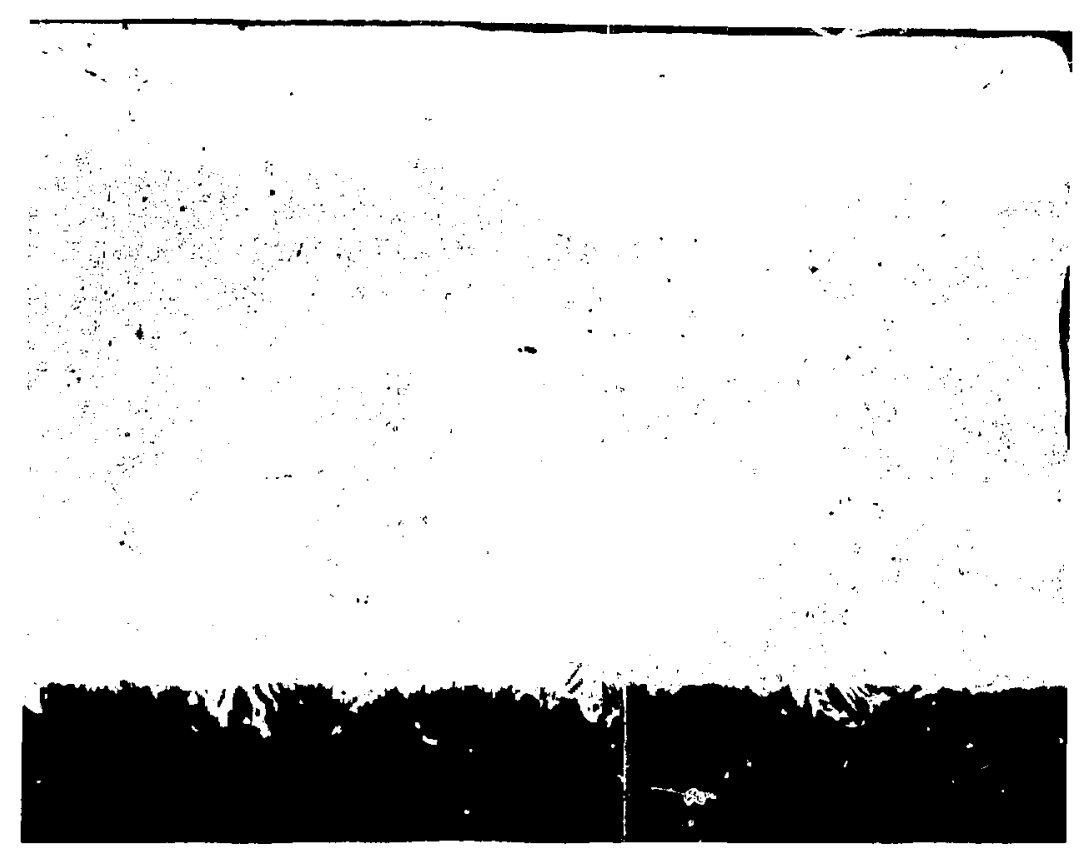

Fig. 4.

Photomicrograph of pyrolytic graphitc brazed to copper with $\mathrm{Ti}-\mathrm{Cu}-\mathrm{Ni}$; magnification = $100 X$.

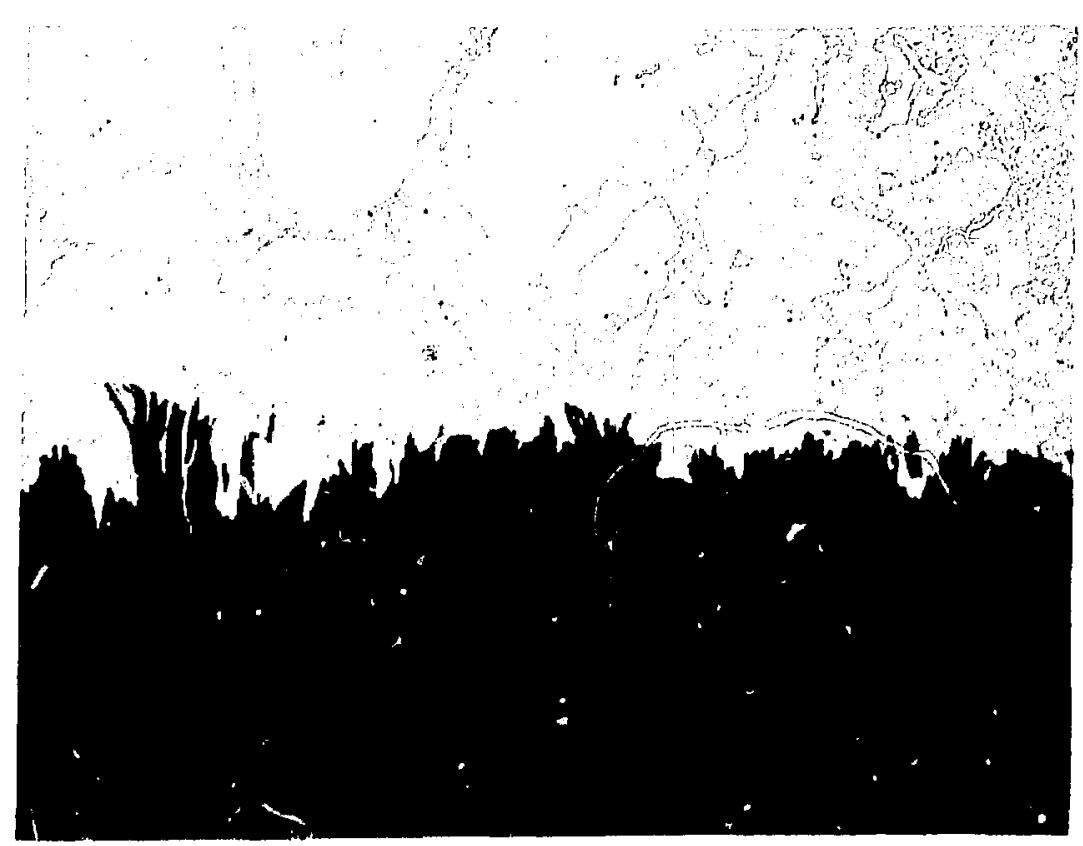

Fig. 5.

Photomicrograph of pyrolytic graphite brazed to copper with $\mathrm{Ti}-\mathrm{Cu}-\mathrm{Ni}$; magnification $=250 X$. 


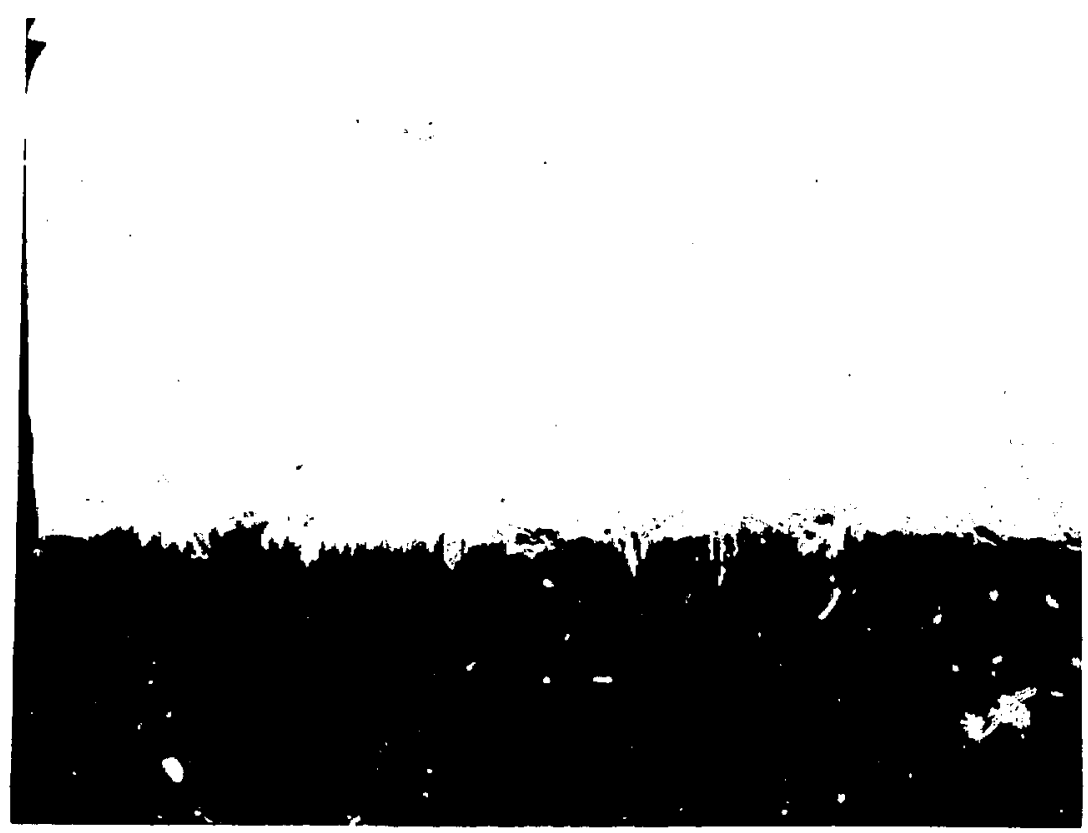

Fig. 6.

Pyrolytic graphite bonded to copper with Ti-Cu-Ni braze alloy.

TABLE II

\section{RESULTS OF HEAT TRANSFER STUDIES}

\section{Material}

${ }^{a}$ Pyrolytic Graphite To Copper/Polyfurfuryl Alcohol With Copper Hybrid

${ }^{a}$ Pyrolytic Graphite to Copper/Polyfurfuryl Alcohol With Copper Hybrid

${ }^{\text {a}}$ Pyrolytic Graphite to Copper/Copper Electroplated Hole, Then BT Braze to Tube

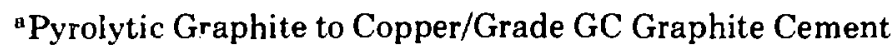

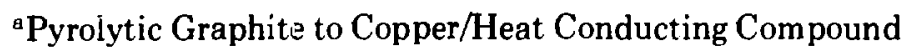

'Pyrolytic Graphite to Copper/Ti-Cu-Sil

'Pyrolytic Graphite to Copper/Ti-Cu-Ni
$\left(\mathrm{W} / \mathrm{cm}^{2}\right)$

aBonds partially failed.

'Survived more than 500 heat flux cycles without failure. 


\section{APPENDIX A}

\section{VARCUM PREPARATION PROCEDURES}

A filled, partially polymerized furfuryl alcohol glue was made with $3.5 \mathrm{~g}$ of -400 mesh aluminum powder, stirred thoroughly into $3.5 \mathrm{~g}$ of catalyzed Varcum 8251 .

Prior to applying the filled glue, the inner diameter of the polygraphite part was coated with unfilled Varcum by brush. This operation was possible because of the short length of the component.

The copper tubing was prepared by sanding the area where the pyrograph te would be glued into place and then the roughened area wiped with a coat of unfilled Varcum. The pyrographite part was slipped into place, and rubbed back and forth along the roughened area until only a thin film of Varcum remained on each mating surface. All excess Varcum was wiped off and the Varcum was cured in an oven.

The aluminum glue was then applied to each treated surface. The pyrographite part was slipped back into place, rubbed back and forth over the roughened area until no glue was forced from the joint, and the finished product wiped clean of excess glue; it was then oven-cured for $15 \mathrm{~h}$ at $250^{\circ} \mathrm{C}$.

The copper-filled glue was prepared in a similar manner. The copper powder used was $\mathrm{Cu}$ $36 \mathrm{D}$, with an average particle size of $\sim 1.5 \mu \mathrm{m}$. The powder was reduced in a mixture of $\mathrm{AR}+\mathrm{H}_{2}$ overnight at $280^{\circ} \mathrm{C}$. The reduced powder was screened using -400 mesh.

The $46 \mathrm{Wt} \%$ copper $/ 54 \mathrm{Wt} \%$ catalyzed Varcum 8251 was cured for $60 \mathrm{~h}$ at $250^{\circ} \mathrm{C}$ in the same manner as the aluminum-filled Varcum.

\section{APPENDIX B}

\section{HEAT TREATMENT HISTORIES}

Ti-Cu-Ni - 76.2- $\mu \mathrm{m}$ foil/ $6.50-\mathrm{mm}$ hole $/ 6.35 \cdot \mathrm{mm}$ tube. Brazed for $20 \mathrm{~min}$ at $1283 \mathrm{~K}$.

BT Braze - 127- $\mu \mathrm{m}$ copper plating on pyrographite/102- $\mu \mathrm{m}$ foil/6.71-hole/6.22-mm tube. Brazed $1103 \mathrm{~K}$ for $15 \mathrm{~min}$.

Heat Compound - 6.35-mm, scribed approximately ore turn per $2.5 \mathrm{~cm}$, the $6.50-\mathrm{mm}$ hole filled with compound. Air-dried for $24 \mathrm{~h} ; 4 \mathrm{~h}$ in furnace at $366 \mathrm{~K}$.

Graphite Cement -5.35 -mm tuk scribed approximately one turn per $2.5 \mathrm{~cm}$, the $6.5-\mathrm{mm}$ hole filled with compound. Baked for $4 \mathrm{~h}$ in a furnace at $373 \mathrm{~K}$.

BT Braze - 102- $\mu \mathrm{m}$ copper plating on graphite $50.8-\mu \mathrm{m}$ foil/6.71-mm hole/6.5 $\cdot \mathrm{mm}$ tube, brazed for $10 \mathrm{~min}$ at $1103 \mathrm{~K}$. 